
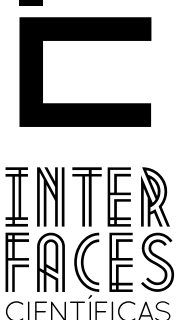

HUMANASE SOCIAIS

\title{
UMA BREVE COMPREENSÃO PSICOLÓGICA SOBRE AS INCONSTÂNCIAS EMOCIONAIS NA GRAVIDEZ E NA MATERNAGEM
}

Matheus Batalha Moreira Nery ${ }^{1}$ Maria Cristielle da Silva Santos

\section{RESUMO}

Este trabalho busca uma breve compreensão psicológica sobre as inconstâncias emocionais na gravidez e na maternagem. Considerando que a emoção revela uma série de comportamentos e atitudes, buscamos compreender como isto implica na relação mãe-bebê. 0 período gestacional é responsável por várias mudanças significativas no universo feminino e o significado que recebe hoje é diferente do símbolo que recebia em séculos passados. Ser mãe nos dias atuais está atrelado a uma série de responsabilidades uma vez que hoje a mulher passou por um processo de independência, podendo escolher entre ser mãe ou não pensando mais na sua inserção e permanência estável no mercado de trabalho. A nossa proposta é demonstrar a importância do conhe-
Álvaro Macel Dantas A. de Almeida

cimento voltado às relações primárias uma vez que estas são mediadoras dos comportamentos de novos sujeitos. Ressaltamos ainda aspectos das mulheres na atualidade bem como a nova concepção do estar grávida, das emoções na gravidez e a relação mãe-bebê. Este estudo poderá servir de construto para futuras pesquisas que ressaltam a importância de um suporte psicológico na gestação e nos primeiros anos de vida do bebê bem como para profissionais da área de saúde que desejam uma compreensão sobre os implicados nesta relação.

\section{PALAVRAS-CHAVE}

Emoções. Gravidez. Maternagem. 


\section{ABSTRACT}

This paper aims to present a psychological understanding about the emotional inconsistencies during pregnancy and motherhood. Considering that the emotion reveals a series of behaviors and attitudes, it is important to try to understand how these factors affect the mother-infant relationship. The gestation period is responsible for several significant changes in the female universe, and the meaning which can be seen nowadays is different from the symbol it used to receive in the last centuries. Being a mother today has been linked to a variety of responsibilities, since the woman has undergone a process of independence, and she can now choose whether she wants to be a mother, or not, taking into consideration her insertion and stable permanence in the labor market. It is proposed the demonstration of the importance of knowledge directed to the primary relationships, since they are mediated by the behaviors of new individuals. We also emphasize aspects of women and the new conception of being pregnant, including the emotions during pregnancy and the mother - infant relationship. This study may help future researches, who are worried about the psychological support in the pregnancy and during the first years of the babies. It is also important for the professionals who work in the health area and want to understand more about the subjects of this relationship.

\section{KEYWORDS}

Emotions. Pregnancy. Motherhood.

\section{RESUMEN}

Este trabajo busca una breve comprensión psicológica sobre las contradicciones emocionales durante el embarazo y la maternidad. Considerando que la emoción revela una serie de comportamientos y actitudes, buscamos comprender cómo esto ocurre en la relación madre-hijo. El período de gestación es responsable de varios cambios significativos en la mujer y el sentido que recibe hoy es diferente del recibido en los últimos siglos. Ser madre hoy en día está vinculado a una variedad de responsabilidades, ya que ahora la mujer pasó por un proceso de independencia, de elegir entre ser madre o no, pensando más en su inserción e en mantenerse estable en el mercado laboral. Nuestra propuesta es demostrar la importancia del conocimiento objetivo de las relaciones primarias, ya que estos comportamientos son mediadores de los nuevos temas. También hacemos hincapié en los aspectos de la mujer de hoy y la nueva concepción de estar embarazada, las emociones durante el embarazo y la relación madre - bebé. Este estudio puede servir como una construcción para futuras investigaciones que pongan de relieve la importancia del apoyo psicológico durante el embarazo y los primeros años de vida del bebé y para profesionales de la salud que desean un entendimiento de los elementos involucrados en esta relación.

\section{PALABRAS CLAVE}

Emociones. Embarazo. Maternidad.

\section{INTRODUÇÃO}

0 presente trabalho busca uma breve compreensão psicológica sobre as inconstâncias emocionais na gravidez e na maternagem. As emoções na maternagem são um dos aspectos de grande relevância a ser

considerado no desenvolvimento do processo de interação mãe-bebê. A função materna está estritamente implicada com a emoção, especialmente no primeiro ano de vida do bebê, uma vez que as experiências de 
vida da mãe desde o seu nascimento e durante a gestação serão mediadoras de um comportamento futuro, o do seu filho.

A gestação é responsável por mudanças no organismo materno, com o objetivo fundamental de adequar o novo ser da mãe. Em virtude disto, durante a gravidez, a mulher passa por mudanças biopsicossociais que, muitas vezes, são difíceis de serem enfrentadas. O histórico de vida do sujeito servirá de base para um comportamento futuro. A forma como a mulher vivencia as suas experiências subjetivas desde a infância, bem como no ventre materno, implica-se em sua relação mãe-bebê (GARY; PAUL; NORMAN, 2000).

Por isso, partindo do princípio de que as emoções revelam uma série de estados sinalizados de formas diferenciadas, tivemos a compreensão de que a mãe

\section{EMOÇÕES}

As emoções seguem padrões de raciocínio e comportamento vitais para o convívio em sociedade. A natureza das emoções é tratada de diferentes formas em diferentes culturas. Só nos últimos anos, pudemos delimitar algo a mais sobre as emoções. Percebe-se, na atualidade, que as vivências emocionais são importantes para a subjetividade do sujeito.

As emoções são reconhecidas no lado direito do cérebro, nas áreas cerebrais que envolvem o controle motivacional, a memória e a cognição, sendo catalogadas e fazendo conexão com os circuitos nervosos por meio dos neurotransmissores. (KELTNER; LERNER, 2000).

As emoções são caracterizadas por traços, os quais se referem ao estilo de respostas emocionais. 0 humor, a raiva, o medo, a irritabilidade fazem parte de um segundo nível de estudo das emoções, aqueles é uma mediadora de comportamentos que também foi mediada, sendo assim buscamos compreender a implicação das vivências emocionais das gestantes e das mães com o seu bebê.

Este estudo poderá servir de construto para futuras pesquisas, que ressaltem a importância de um suporte psicológico na gestação e nos primeiros anos de vida do bebê, bem como para profissionais da área de saúde que desejem uma compreensão sobre os implicados nesta relação.

No decurso do trabalho, apresentaremos a importância do conhecimento voltado às relações primárias, uma vez que estas são mediadoras dos comportamentos de novos sujeitos. Ressaltamos ainda aspectos das mulheres na atualidade, bem como a nova concepção do estar grávida, das emoções na gravidez e da relação mãe-bebê.

que correspondem às tendências particulares e subjetivas do sujeito. Existe ainda um terceiro nível de estudo, que são os dos traços positivos de humor, como gratidão, ternura, felicidade, que causam um bem- estar subjetivo (KELTNER; LERNER, 2000).

O núcleo das avaliações das emoções é regido de acordo com as experiências vivenciadas. As emoções possuem um papel significativo na gravidez uma vez que todo o relacionamento familiar é norteado por novas atitudes e responsabilidades, sendo estabelecidas no casal as funções maternas e paternas. Os pais se percebem vulneráveis emocionalmente, sendo vivenciada uma mudança no papel social.

Com o objetivo de avançar nos estudos sobre as emoções nas gestantes e nas mães, abordaremos o presente tema, realizando interfaces entre a psicologia e a gravidez, a fim de compreender o funciona- 
mento do psiquismo de mulheres na gestação e na maternagem e como elas se desenvolvem na socieda- de, a partir das transformações que existem em seu novo modo de vida (COUTINHO; SARAIVA, 2008).

\section{A MULHER E O ESTAR GRÁVIDA}

A mulher em seu contexto histórico vivenciou uma massa de acontecimentos e moldes de comportamentos estabelecidos por figuras masculinas. Até meados do século $X X$, as mulheres eram submissas às imposições de seus homens, vivenciando uma posição de hierarquia social.

O novo ser de sexo feminino já nascia com o seu destino estabelecido por seu pai uma vez que, ao nascer, era prometida a uma figura de sexo masculino sem possuir direito de escolha. Sendo assim, a vivência da feminilidade estava atrelada à maternagem e à procriação. Os séculos foram passando e a mulher foi lutando por seus direitos e hoje pode escolher entre ser mãe ou não (ALTTIMAN; COSTA, 2009).

Na metade do século $X X$, a mulher começou a se inserir no mercado de trabalho, gerando renda para si própria e competindo com homens no mercado. Atualmente, ela conquistou alguns objetivos tão sonhados para a sua construção enquanto sujeito sociável, uma vez que pode trabalhar, votar, namorar, se casar, se separar e se casar novamente.

Durante a luta mundial das mulheres pelos seus ideais, alguns acontecimentos foram marcantes para a liberdade de escolha feminina. Dentre eles, destacamos alguns: em 1873, Dona Francisca Senhorinha da Motta Diniz tentava resgatar a história das mulheres brasileiras advogando então o sufrágio feminino. Em 1879, o Governo do Brasil abriu as instituições de ensino superior às mulheres. Em 1887, Rita Lobato Velho Lopes, tornou-se a primeira mulher médica no Brasil. Em 1893, na Nova Zelândia, foi concedido o direito ao voto fe- minino. Em 1910, foi criado o partido Republicano Feminino. Em 1932, Getúlio Vargas promulgou o novo Código Eleitoral, garantindo o direito ao voto das mulheres brasileiras. A partir daí, os direitos femininos foram avançando progressivamente (ALTTIMAN; COSTA, 2009).

A gravidez, para as mulheres do século XXI, apresenta-se, em sua maioria, não sendo mais o único ou o primeiro objetivo. Percebe-se que hoje ela tem primeiramente a utopia de ter um emprego estável, com uma renda financeira que lhe propicie o anseio de seus desejos para que, a partir daí, reflita entre querer ou não ter um filho.

A mulher moderna é aquela trabalhadora e independente, quebrando paradigmas, podendo ser também mãe, esposa e dona de casa, mas desde que seja por vontade própria. A identidade feminina é norteada por diversos contextos e símbolos, possuindo sempre os positivos e os negativos.

A primazia feminina atual tornou a mulher um ser multifuncional, sem abandonar a sua feminilidade e criatividade. Com a junção destes fatores, vem o desejo de ser mãe, decisão esta que passa por uma série de mudanças em seu atual status e independência (ALTTIMAN; COSTA, 2009).

A gravidez é um estado fisiológico, sendo de fundamental importância o seu diagnóstico. $\mathrm{Na}$ vida das mulheres, há poucas experiências da vida que podem despertar emoções de alegria tão absolutas ou dores que causam profundo desespero. E para todos os médicos encarregados do trata- 
mento clínico de mulheres em idades reprodutivas, o conhecimento da gravidez é fundamental para o diagnóstico e o tratamento apropriados de todas as doenças.

Muitas manifestações das adaptações fisiológicas normais da gravidez são facilmente reconhecidas e constituem importantes indícios para o diagnóstico e avaliação do seu processo. Algumas alterações da gravidez são previsíveis a tempo para constituir marcos importantes que assinalam o tempo de acomodações da grávida ao crescimento, à maturação e à função do útero e do concepto.

No processo de gravidez, as mulheres passam por algumas alterações endocrinológicas, fisiológicas, anatômicas e psicológicas que acompanham a gravidez, modificando a forma de viver da mãe. Esses sinais e sintomas são classificados em três grupos: evidência presuntiva, sinais prováveis e sinais positivos da gravidez.

A evidência presuntiva de gravidez baseia- se principalmente em sintomas subjetivos que incluem náuseas com ou sem vômito, distúrbios da micção e percepção de movimento fetal. Também fazem parte desta evidência alterações anatômicas nas mamas, alterações da cor da mucosa vaginal, aumento da pigmentação cutânea e desenvolvimento de estrias abdominais.

É importante ressaltar que, na gravidez, uma série de sintomas fisiológicos e psicológicos são responsáveis por grandes transformações na mãe. Dentre as mudanças fisiológicas, a que mais se faz presente é a gonadotropina coriônica, que são principalmente isoformas com quantidades relativamente diminuídas de ácido siálico, que atua através do receptor do hormônio estimulante da tireoide, acelerando a captação de iodo. Os distúrbios da micção durante o primeiro trimestre ocorrem devido ao útero estar em crescimento, exercendo pressão sobre a bexiga, podendo causar micção fre- quente. Conforme a gravidez progride, a frequência de micção diminui. 0 sintoma de miç̧ão frequente reaparece próximo ao fim da gravidez. Existem ainda as alterações das mamas, do tamanho e posição do coração, a frequência e o débito cardíaco, que podem modificar de forma temporária o estilo de vida das mães. Além disso, a pressão arterial se modifica e a venosa começa a aparecer bem como aparecem também modificações respiratórias e gastrointestinais. (GARY; PAUL; NORMAN, 2000).

As mudanças fisiológicas geram algumas alterações emocionais uma vez que alguns dos estados fisiológicos citados acima podem desenvolver na mulher uma baixa autoestima causada por uma mudança do seu estilo de vida. A exemplo, existem ainda outros fatores que modificam a rotina materna como a fadiga. 0 movimento fetal, quando ocorre, é algo que, na maioria das vezes, é um marco emocional da vida materna, pois é quando a mãe sente pela primeira vez que está gerando um novo ser que vive dentro dela.

O feto representa um papel dinâmico na gravidez. No passado, ele era considerado um passageiro passivo desta unidade, pois acreditavam que ocupava apenas um espaço de dependência do outro, sua mãe, não atuando e que este espaço não era responsável pela constituição do seu self. No avanço dos estudos das relações primárias, foi compreendida a magnitude das contribuições fetais para a regulação da gravidez humana, sendo importante reconhecer que, enquanto o embrião-feto goza de uma posição de proteção do meio externo que nunca mais experimentará na vida, já estão sendo estabelecidos laços e vínculos constitutivos da sua personalidade enquanto ser psicologizável, sendo a forma dinâmica na orquestração do seu próprio destino. 


\section{EMOCÕ̃ES NA GRAVIDEZ}

Em um estudo de cunho psicanalítico, Mellor (2011) compreendeu que as mulheres possuem uma capacidade de sublimar tanto como mulheres quanto como mães. A sublimação corresponde ao redirecionamento das energias instintivas para objetos socialmente mais aceitáveis. Na sublimação da maternagem, o objeto amado ocupa um lugar do Eu, o qual assume uma função do passado infantil, sendo o Eu adulto identificado no inconsciente como a mãe. Quando as mulheres se descobrem como gestantes, guardam consigo diversos significados, vivenciados em diferentes formas.

O período gestacional está acometido por um processo de mudanças biopsicossociais, que será regido a partir da forma em que a mãe é mediada por seu histórico de vida. Muitas mães assumem a maternagem, utilizando uma energia libidinal canalizada, transformando-a em uma postura socialmente útil e desejada, sendo esta uma maneira de vivenciar o seu passado. Esta atividade, apesar de gerar emoções positivas através de vivências desejadas, poderá gerar alguns conflitos, como se tratasse de uma infidelidade conjugal, onde o cônjuge pode sentir-se o objeto excluído (MELLOR, 2011).

Algumas mães que vivenciaram emoções negativas em seu histórico de vida, às vezes, começam a desenvolver uma fantasmatização própria, pois vivenciam a sua angústia como sendo vampiras, castradoras, como se tivessem o seu seio mutilado, destruídas, com um objeto esvaziado, ressurgindo então uma problemática pré-genital anal e até mesmo oral (MELLOR, 2011).

Sabemos que, durante a gravidez, o casal passa por uma série de mudanças no relacionamento, algumas adaptações para o nascimento do bebê começam a reger de forma diferente a vida do casal. Uma das mudanças no casal refere-se à abstinência sexual, sendo vivenciada de formas diferenciadas por cada sujeito; existem aquelas mães que se sentem em estado de completude, pois este é um momento de encontro com um novo ser que habita seu interior.

Durante a gestação, as mulheres passam por três momentos da etapa gravidez puerperal. O primeiro grande momento é o da transformação da filha em mãe, o segundo é o da transformação da autoimagem corporal e o terceiro momento faz referência à relação entre a sexualidade e a maternidade. Algumas mulheres, durante a gravidez, vivenciam oscilações no seu humor, conseguindo permear de forma instantânea da euforia à tristeza profunda. Existem mulheres que conseguem se manter estáveis a todas estas mudanças, mas outras não conseguem admitir para si mesmas que merecem ajuda da família. Apresentando uma tristeza materna de uma forma geral, sentindo que perdeu o seu lugar de filha, sem que tenha segurança no papel da mãe, sente que seu corpo está irreconhecível (CARLESSO; SOUZA, 2011).

O bebê para a mãe se torna um terceiro elemento entre ela e o marido, forma-se o triângulo que remete o casal às suas próprias questões com seus pais. Este novo ser poderá ser percebido em contextos variados como se fosse exaltar o narcisismo do casal ou ainda como um ser a interferir na relação. Se este for visto como no último caso, a mulher poderá apresentar sintomas negativos de forma intensa, necessitando de uma intervenção mais brusca de um profissional, para prevenir uma depressão pós- parto.

Irritabilidade, mudanças bruscas de humor, indisposição, tristeza, insegurança, baixa autoestima e sensação de incapacidade de cuidar do bebê são alguns sintomas que algumas mães sentem. Mas as maiores implicações se encontram em como são vivenciados e elaborados estes sintomas. A repercussão emocional do puerpério na vulnerabilidade das 
mulheres vai depender do seu contexto de vida, das suas condições sócio econômicas, das relações interpessoais e do suporte ou não de uma rede de apoio neste período, de modo a possibilitar uma vivência de puerpério menos desgastante, pesada e estressante (COUTINHO; SARAIVA, 2008).

As preocupações com relações aos limites e possibilidades de um futuro melhor para seus filhos, em meio a um cenário de profundas desigualdades sócioeconômicas, poderá produzir na mãe sentimentos positivos do humor, tendo desejos de melhores condições de vida para seu filho, indo buscar estas melhorias, ou ainda sentimentos de tristeza, infelicidade, desilusão, angústia e impotência, gerados pelos limites financeiros e falta de perspectiva futura dessas mulheres em oferecer melhores condições para uma vida digna a seus filhos.

A sociedade, na maioria das vezes, afirma que a gravidez une o casal, mas nem sempre isso ocorre. A percepção que muitas mulheres têm do seu relacionamento na gravidez pode estar relacionada com a sintomatologia da depressividade durante a gravidez e no pós-parto. As mulheres que tiveram as avaliações de emoções mais negativas durante a gravidez possuem uma tendência à depressão durante o puerpério e no pós-parto (COUTINHO; SARAIVA, 2008).

Outro aspecto muito importante é o fato de que, na sociedade em que vivemos, cada vez mais as mulheres vem assumindo posições de liderança nos espaços públicos e privados. Se formos analisar a história da mulher, veremos constantes movimentos de revolução devido à busca dos direitos femininos. Sendo assim, é de grande relevância que ter um filho, para muitas mulheres, hoje pode ocasionar sentimentos divergentes, pois para algumas o filho surge como complemento do seu ego, exaltando o seu narcisismo, tornando-a um ser completo, pois, além de estar firmada no mercado de trabalho, pode gerar um novo ser; mas, para outras mulheres, a gravidez poderá vir acompanhada por frustrações significativas, privações afetivas, econômicas e reais, aumentando a raiva, o ressentimento e a culpa por gerar este novo ser dificultando a relação da díade mãe-bebê.

\section{RELAÇ̃̃O MÃE-BEBÊ}

A partir das relações parentais, se constitui o verdadeiro selfo bebê e a base para a sua personalidade. Sendo assim, se pretende ampliar o conhecimento da relação mãe-filho, mãe-bebê, materno-fetal bem como a afetividade e suas implicações na gravidez (BERNARDINO; LAZNIK; ARAÚJO, 2011).

Para que o pequeno sujeito possa se desenvolver, ele precisará se apegar a uma figura para, então, estabelecer laços pulsionais com o outro. No primeiro momento, a figura que lhe é apresentada é o agente materno, o qual, com passar do tempo, será também responsável por sua relação no campo do outro, sendo um lugar simbólico. 0 desenvolvimento desse laço

não é inato, ele precisa ser aprendido na relação materna, sendo uma forma complexa de desenvolvimento, já que estão envolvidos outros aspectos da vida materna e do histórico de vida da mãe, figura muito importante nesse processo.

Indagar ou pensar no "amor materno" implica dizer que ele não está livre de ambivalências. Na psicanálise, o amor da mãe por seu filho traz consigo desdobramentos que irão explicitar futuros comportamentos, uma vez que esse afeto é construído.

Uma mãe só será possível se tomarmos como referência uma estrutura que a autoriza, que a faz e que a 
torna possível enquanto mãe, estando atrelada à função paterna. A mãe é primordialmente o Grande Outro para a criança, sendo de fundamental importância a incorporação da função paterna aos seus cuidados, já que trazem consigo alguns interesses particularizados, embasado nas próprias faltas da mãe (BERNARDINO; LAZNIK; ARAÚJO, 2011).

São-nos propiciadas diversas formas de poder observar o Ser Mãe: a mãe real da gestação, do parto e do corpo a corpo com o bebê; a imaginária toda poderosa que ainda não foi castrada, da criança pré-edípica; e ainda a mãe presente em sua ausência, enquanto significante, sempre irredutível (ABRAS, 2011).

Quando uma mulher encontra o seu tipo de “Mãe”, abre espaço para uma disputa de sentimentos como devotamento e dívida, uma vez que ela se dedica ao seu filho ao mesmo tempo em que se cobra por achar que deve ser feito mais, se sentindo com uma dívida, gozo e angústia, pois tem prazer e insegurança momentânea com o futuro. A mãe estabelece laços com o seu filho, mas, até chegar a este nível, é porque ela compreendeu o seu próprio narcisismo e extraiu algo dele (ABRAS, 2011).

O amor é fundamental na relação mãe-bebê e, para que esse sentimento exista, será necessário que a mãe tenha um narcisismo suficientemente sólido, já que este "sacrifício" aparece na mesma medida que o filho estará enriquecendo o narcisismo dos pais. 0 amor e o gozo estão ligados por intermédio do desejo. Se existir falha na relação mãe-bebê, deverá haver intervenção de um profissional capacitado.

Uma mãe pode amar de diversas formas e estas são as vicissitudes da relação dela com o seu filho: amar doando a falta; amar em excesso e sem limites; amar sem correspondência; e desamar, não conseguindo amar.

O discurso familiar é muito importante para o desenvolvimento da personalidade e da subjetividade da criança. Quando este for depressivo, será um grande contribuinte para uma personalidade com depressividade. Vale ressaltar que a figura paterna assume posições também constitutivas. 0 pai aparece como alguém que deve dar um suporte à mãe, o filho deverá perceber e sentir que o seu pai sente prazer ao estar ao seu lado, que ele deseja estar com ele.

O estado depressivo da mãe pode repercutir negativamente no estabelecimento das primeiras interações com o bebê e, consequentemente, no desenvolvimento afetivo, social e cognitivo da criança. Com a depressão pós-parto da mãe, o bebê perde emocionalmente sua mãe, pois ela, ao mudar sua atitude emocional, altera o significado que o bebê tem da mãe, como um objeto bom. Subjetivamente, quando a mãe deprimida rompe o contato visual com o bebê e este pode ser interrompido, o bebê tenta se aproximar da mãe por meio da identificação e da imitação, uma vez que esta é responsável por lhe inserir no mundo simbólico (SCHWENGBER; PICCININI, 2003).

0 bebê se caracteriza como um reanimador, pois diante de uma situação de depressão, tenta fazer com que a mãe volte à vida. 0 estado afetivo da mãe pode repercutir também na sua vocalização para o bebê. As mães deprimidas apresentam vocalizações mais baixas para responder as vocalizações dos bebês de quatro meses, apresentando muitas variações e pausas, ocorrendo o contrário nas mães em estado afetivo positivo.

A mãe deprimida contribui para desenvolver um estilo depressivo no bebê; já as mães responsivas, expressivas e falantes podem desenvolver no bebê uma tendência a se afastar fisicamente e apresentam mais comportamentos negativos para chamar atenção. Quando as mães não estão com afeto depressivo, os bebês evidenciam mais comportamentos positivos e brincam mais próximos à mãe (SCHWENGBER; PICCININI, 2003).

Com isso, se ressalta a importância de um diagnóstico correto de gravidez, bem como o suporte 
emocional de toda a família durante este processo e nos primeiros anos de vida do bebê, já que a mulher, enquanto mãe, está passando por algu- mas mudanças no seu estilo de vida assumindo um novo papel, o qual será mediador de futuros papéis psicologizáveis.

\section{CONCLUSÃO}

Em linhas gerais, o estudo que realizamos para a produção deste trabalho, nos possibilitou uma breve compreensão psicológica sobre as inconstâncias emocionais na gestação e na maternagem. Percebemos que o percurso da gravidez pode ser permeado inicialmente por sentimentos de tristeza, já que esta assume um novo papel, construindo uma nova identidade. A alegria aparece presente no momento em que a mãe assume uma concretude de atitudes e comportamentos quanto a si mesma e ao seu bebê. É importante ressaltar que este estudo é pouco analisado e que implica em vidas futuras, uma vez que o bebê é um ser sensivel e que necessita de referências que the incluam em um mundo simbólico, o qual corresponde ao estabelecimento dos vínculos e dos moldes culturais. Dessa forma, sugerimos que é de fundamental importância um suporte psicológico durante a gravidez e nos primeiros anos de vida do bebê. Com certeza, este estudo não termina por aqui uma vez que pode servir de construto para futuras pesquisas que ressaltem a importância de um suporte psicológico na gestação e na maternagem bem como para profissionais da área de saúde que desejam uma compreensão sobre os implicados nesta relação.

\section{REFERÊNCIAS}

ABRAS, R; GOUVÊIA, M. “'A vida se engole a seco": reflexões sobre a depressão na contemporaneidade. Estudos de Psicanálise, n. 35, 2011.

ALTTIMAN, C. N. ; COSTA, S. G. Revolução Feminina: As conquistas da mulher no século XX. Jandira, Trabalho de Conclusão do Curso de Administração de Empresas. Faculdade Eça de Queirós. 2009.

ANTÔNIO, V. E. et al. Neurobiologia das Emoções. Revista Psiquiatria Clínica, São Paulo- SP, n. 35(02), 2008.

BERNARDINO, L. M. F. ; LAZNIK, M. C. ; ARAÚJO, G. $X$. "As vicissitudes do encontro mãe/bebê: um caso de depressão", Estudos de psicanálise, Belo Horizonte-MG, n. 35, 2011.
CARLESSO, J. P. P. ; SOUZA, A. P. R. Dialogia Mãe- FiIho Em Contextos de Depressão Materna: Revisão De Literatura. São Paulo, 2011. Disponível em: http:// www. scielo. br/pdf/rcefac/2011nahead/76-10. pdf. Acesso em: 10 fev. 2012

COUTINHO, M. P. L. ; SARAIVA, E. R. A. "Depressão pós- parto: considerações teóricas”, Estudos e Pesquisas Em Psicologia, UERJ, n. 3, 2008.

GARY, F. C. ; PAUL. C. M. ; NORMAN, F. G. Williams Obstetrícia, 20. edição. Editora Guanabara. Koogan S. A. Rio de Janeiro, 2000.

KELTNER, D. ; LERNER, J. S. Emotion. Berkeley: University of California/Harvard University, 2000. 
MELLOR, S. M. "A maternidade é uma forma de sublimação?”, Estudos de psicanálise. Belo Horizonte-MG, n. 35, 2011.

SCHWENGBER, D. D. S. ; PICCININI, C. A. "O impacto da depressão pós-parto para a interação mãe-bebê", Estudos de Psicologia, Campinas-SP, n. 8(03), 2003. 